\title{
Torularhodin and Torulene: Bioproduction, Properties and Prospective Applications in Food and Cosmetics - a Review
}

\author{
Liliana Zoz $^{1,2}$, Julio Cesar Carvalho ${ }^{1}$, Vanete Thomaz Soccol ${ }^{1}$, Thais Costa Casagrande ${ }^{2}$ \\ and Ligia Cardoso ${ }^{2 *}$ \\ ${ }^{1}$ Programa de Pós Graduação em Engenharia de Bioprocessos e Biotecnologia; Universidade Federal do Paraná; \\ Curitiba - PR - Brasil. ${ }^{2}$ Mestrado Profissional em Biotecnologia; Universidade Positivo; Curitiba - PR - Brasil
}

\begin{abstract}
Torularhodin and torulene are two widespread microbial carotenoids with relatively few studies, as compared to other nutraceutical carotenoids such as $\beta$-carotene, lycopene and astaxanthin. Several genera of microorganisms produce it in high concentration (up to $0.1 \%$ of the cell dry weight), probably as a protection against photooxidation and free radicals. These pigments, which differ by a terminal carboxylic group, have provitamin-A activity and, being red, have potential use as food and cosmetic color additives. Several factors affect the biosynthesis of these substances, including: the composition of culture media, light irradiation, which may enhance the carotenoid production up to $25 \%$ of the non-irradiated cultures, and temperature, which changes the carotenoid balance towards more of the acidic carotenoid (torularhodin) or the hydrocarbon (torulene). The biomass may be directly extracted using non polar solvents such as hexane or a hexane-acetone mixture, without need of cell disruption. Extensive purification is not needed for using the pigments as food or cosmetic additives, but it is still necessary to evaluate the bioactivity of the pigments in humans.
\end{abstract}

Key words: carotenoid, antioxidant, microorganism, biopigment

\section{INTRODUCTION}

Torulene and torularhodin are carotenoid biopigments that are found in several red yeasts, such as Rhodotorula glutinis and Sporobolomyces ruberrimus. These microorganisms also produce $\beta$-carotene, although in smaller amounts. The total production and the proportion of the three carotenoids depend on the incubation conditions (Tinoi et al. 2005). Torularhodin shows a considerable antioxidant activity (Breierová et al. 2008) that helps the stabilization of membranes under stress conditions (Gorbushina et al. 2008). These carotenoids are beneficial because they are precursors of vitamin A and hormones and they have antiaging and antioxidant capacity. They may also prevent certain types of cancer, and enhance the immune system (Buzzini et al. 2005; Breierová et al. 2008). These possibilities make torularhodin and torulene a hot research topic in carotenoid biotechnology. The production and use of these pigments is still in developmental stage. It is only recently that active search for producer strains started, and there is not yet industrial production, no consensus about best culture media and only partial information in terms of the regulation of its biosynthesis in the cultures, through the manipulation of physico-chemical conditions. While biosynthesis pathways for the production are well studied, the downstream and physiological effects of these pigments are still under study, and are an absolute requirement for

*Author for correspondence: laccardoso@yahoo.fr 
widespread use of these pigments to occur. This review compiles relevant information about torularhodin and torulene bioproduction, and the perspectives of its future uses.

\section{TORULENE AND TORULARHODIN}

Carotenoids are a class of natural pigments which are polyunsaturated, fat soluble, and mostly found in the plants, algae and photosynthetic bacteria. Carotenoids play an important role in the photosynthetic process. They are also found in non-photosynthetic bacteria, yeast and fungi, protecting these organisms from the damages generated by light and oxygen ( $\mathrm{Ni}$ et al. 2005). These molecules are tetraterpenes whose color ranges from yellow to orange and up to red (Aksu and Eren 2005).

Carotenoids are widespread in nature and have a large diversity, but some are more common $(\beta$ carotene, lycopene, lutein, etc.), being found in several vegetables and animal tissues. Karrer et al. (1951) had reported some substances that they described as "non-familiar" carotenoids, including torularhodin, which showed action as pro-vitamin A. Gribanovski-Sassu and Foppen (1968), described torularhodin as a product of the oxidation of torulene, which was derived directly from $\gamma$-carotene. Subsequently, Moore et al. (1989) reported torularhodin in R. mucilaginosa as a carotenoprotein, a complex that was expected to be more water-soluble and stable than the free carotenoid. The molecular structures of torularhodin and torulene are presented in Figure 1.
The most significant characteristic of carotenoids is the conjugated double bond system that determines their color and biological action (Irazusta et al. 2013). Torulene, the major carotenoid of $R$. mucilaginosa, is an interesting carotenoid for industrial applications. It has 13 double bonds, has red color, in contrast to other carotenoids produced by the microorganisms such as $\beta$-carotene, which has a yellow to orange color, depending on the concentration (Maldonade et al. 2008), and astaxanthin, which gives the characteristic salmon color (Moriel et al. 2005). Torulene and torularhodin have one $\beta$-ionone ring and a longer polyene chain than that of $\beta$-carotene (Sakaki et al. 2001). Besides that, torularhodin is one of the few carotenoids with carboxylic acid function, and shows a considerable antioxidant activity (Sakaki et al. 2002). This characteristic accounts for its polar properties. The absorption maxima of torulene and torularhodin varies between 400 to $550 \mathrm{~nm}$, thus giving the characteristic red appearance of the pigment solution. Table 1 present absorption maxima for both these.

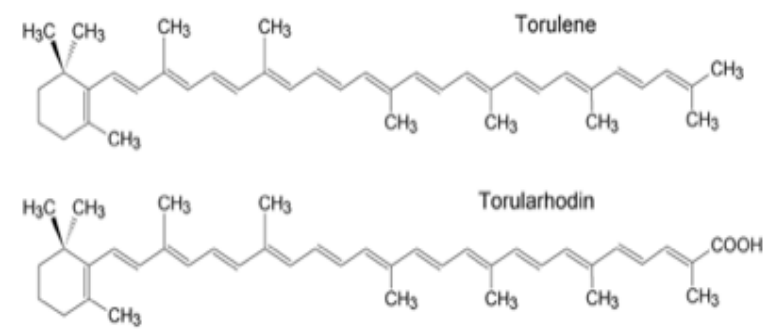

Figure 1 - Molecular structures of torularhodin and torulene.

Table 1 - Absorption maxima and extinction coefficients for torulene and torularhodin.

\begin{tabular}{|c|c|c|c|}
\hline Pigment & Absorption (nm) & Extinction coefficient $\left(E^{1 \%}{ }_{1 \mathrm{~cm}}\right)$ & Reference \\
\hline \multirow{6}{*}{ Torulene } & $458-484-518$ & 2680 (petroleum ether) & (Villoutreix 1960) \\
\hline & 486 & 2690 & (Valadon and Cooke 1962) \\
\hline & 485 & 2680 (hexane) & (Bhosale and Gadre 2001) \\
\hline & $450-484$ & - & (Park et al. 2007) \\
\hline & $460-485-518$ & - & (Weber et al. 2007; Maldonade et al. 2008) \\
\hline & $465-490$ & - & (Maoka 2009). \\
\hline \multirow{4}{*}{ Torularhodin } & $474-500-533$ & 2580 (petroleum ether) & (Villoutreix 1960) \\
\hline & $468-502-539$ & 2040 (hexane) & (Foppen and Gribanovski-Sassu 1969) \\
\hline & $470-495-524$ & - & (Weber et al. 2007; Maldonade et al. 2008) \\
\hline & 501 & - & (Park et al. 2007) \\
\hline
\end{tabular}

\section{Sources of Torulene and Torularhodin}

A number of microorganisms, including bacteria, algae, mold and yeasts, produce a broad range of carotenoids, including $\gamma$ - and $\beta$-carotene, torulene, lycopene and astaxanthin (Foppen and Gribanovski-Sassu 1969, Irazusta et al. 2013). 
Villoutreix (1960) showed that the yeast Rhodotorula mucilaginosa produced four main pigments: torularhodin, torulene, $\beta$-carotene and $\gamma$-carotene. Moore et al. (1988) found torularhodin in the same yeast. Torulene was also found in a nematophagous fungus, Arthrobotrys oligospora (Valadon and Cooke 1962). The first time a ketocarotenoid with the characteristics of torularhodin had been isolated as a fungal metabolite was in 1966, from Epicoccum nigrum (Gribanovski-Sassu and Foppen 1968). Two years later, this fungus was discovered to produce torularhodin from $\gamma$-carotene (Gribanovski-Sassu and Foppen 1968).

All animals that have these pigments on their bodies got them by absorption of food, like fishes and flamingos (Bjerkeng et al. 2007). In 1986, both pigments were found in butterflies. Probably the $\gamma$-carotene absorbed from the food is converted into torulene, which in turn is converted into torularhodin in these insects (Czeczuga 1986). Torulene was also found in Gibberella fujikuroi (Avalos et al. 1988). It was also observed that factors such as light, mycelial age and mutation affected the total amount of terpenoids formed and also altered the relative amounts produced in the three classes of terpenoids investigated. Lichens of the species Nephroma laevigatum were demonstrated to contain torulene too (Czeczuga et al. 1986), and yet another fungus, Scutellinia umbrarum, was found to have torulene as its major carotenoid. With this study, it was possible to identify that carotenogenesis was photodependent in this fungus (Schrantz and Lemoine 1995).

It was only in 1990s that the torulene and torularhodin were regarded as potentially useful substances by their own right (Razavi and Marc 2006). Before that, they were mentioned as uncommon carotenoids (Moore et al. 1989). In the last decade, the studies about the production of these pigments has increased, especially motivated by their potencial benefits (Razavi and Marc 2006). There are many other microorganisms that synthesize torularhodin and torulene, like: Cystofilobasidium infirmominiatum, C. capitatum (Herz et al. 2007), Sporobolomyces roseus (Herz et al. 2007; Weber et al. 2007), Rhodotorula rubra (322.6 $\mu \mathrm{g} / \mathrm{L}$ medium) (Ungureanu et al. 2012). The fungus Neurospora crassa produces torulene and torularhodin and is widely used in research (Hausmann and Sandmann 2000; Estrada et al. 2008).
Role of torulene and torularhodin in Microorganisms

In the process of photosynthesis, chromophores absorb light, and the energy absorbed is transferred to chlorophyll. This antenna function of carotenoids extends the wavelength range accessible for the collection of light for uphill transmembrane proton transport (Balashov et al. 2005). However, microbial carotenoids have biological significance other than their antenna function in photosynthesis. These other functions have been deduced from their presence in fungi and non-photosynthetic bacteria (Sakaki et al. 2002).

The most important physiological role of carotenoids in red yeasts may be as antioxidants in situations of high oxidative stress (Madhour et al. 2005), and also as light-quenching pigments (Irazusta et al. 2013). The important protective role of carotenoids in the oxidative stress response caused by reactive oxygen species has also been demonstrated in the alga Haematococcus pluvialis (Méndez-Álvarez et al. 2000).

A study demonstrated that a mutant, $R$. mucilaginosa RCL-11 strain, expressed three major carotenoids identified as torularhodin, torulene and $\beta$-carotene in major quantities (Irazusta et al. 2013). Another mutant, R. glutinis no. 21, increases its production of torularhodin for protection against membrane impairment by activated oxygen molecules, reinforcing the idea that torularhodin has an antioxidant role in the cells (Sakaki et al. 2000).

The red yeast Dioszegia under oxidative stress enhances the production of torularhodin (Madhour et al. 2005). $R$. glutinis isolated from soil are shown to have low resistance to light, and their growth is inhibited by illumination with white light of weak intensity. During this process, torularhodin was abundantly biosynthesized in the yeast, indicating that increased the production of torularhodin played an important role in defense against peroxyl radicals and singlet oxygen. Acquisition of the capacity to synthesize torularhodin, an agent that enables the yeast to grow in various environments, appears to have been crucial. That is, the capacity to biosynthesize torularhodin, which have a scavenging activity towards peroxyl radicals and singlet oxygen, is significant for the survival of a yeast species with wide distribution in nature (Sakaki et al. 2002).

The same was proved by other studies like one made by Herz et al. (2007), where they found that 
the production of torulene and torularhodin in pure culture was dependent on enhanced oxidative stress, suggesting a cell protective role. Moliné et al. (2010) tested the cell UV-B resistance in different strains of the yeast Rhodotorula mucilaginosa. A positive correlation between total carotenoids and survival to UV-B radiation was found, but when individual carotenoid concentrations were tested, only torularhodin was found as significantly related to survival against UV-B.

Moore et al. (1989) reported that the addition of $\beta$-carotene completely prevented hyperoxiainduced cytotoxicity in $R$. mucilaginosa cells in which carotenogenesis had been blocked by diphenylamine. Therefore, the conclusion was that in yeast, carotenoids were an effective antioxidant when the dissolved oxygen concentration was high.

\section{Carotenoid Biosynthesis}

Carotenoid biosynthesis is known to follow the condensation of isoprenoid units into phytoene, a 40-carbon atoms backbone. This molecule is then converted, depending on the organism, into other acyclic carotenoids such as lycopene, and eventually one or both molecule terminals are cyclized into a ionone ring such as in $\beta$-carotene. There are two independent cyclization routes giving as end products either torulene or $\beta$-carotene (Hausmann and Sandmann 2000). It was found that torularhodin could be regarded as an oxidation product of torulene, which was derived directly from $\gamma$-carotene (GribanovskiSassu and Foppen 1968). Figure 2 shows the most representative steps and products in carotenoid biosynthesis.

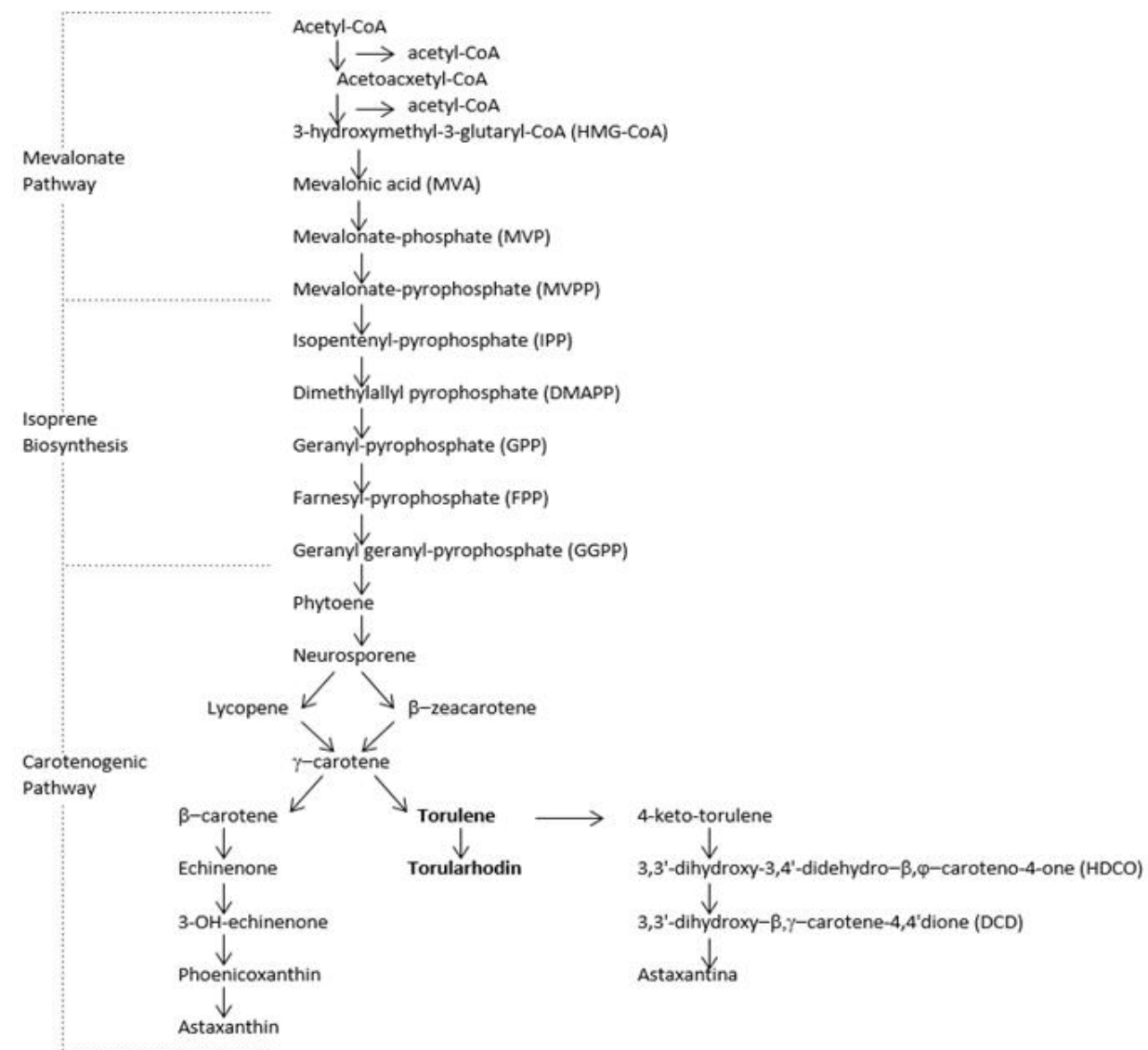

Figure 2 - Biosynthesis of carotenoids, especially Torulene and Torularhodin.

Phaffia rhodozyma, another red yeast, produces in large scale the carotenoid pigment astaxanthin, but this yeast has also the ability to produce torulene in its metabolic pathway (An et al. 1999). The same applies to another astaxanthin producer, the alga Haematococcus pluvialis (Méndez-Álvarez et 
al. 2000). These pigments can be found mainly distributed in fish because of its food intake, vegetable and microorganisms, like especially $R$. glutinis (Sakaki et al. 2002; Herz et al. 2007; Weber et al. 2007).

Foppen and Gribanovski-Sassu (1969) tested the effect of diphenylamine on carotenoid production in E. nigrum (Foppen and Gribanovski-Sassu 1969). Diphenylamine, a specific inhibitor of carotenogenesis, was added to the cultures at the onset of incubation. The mechanism of diphenylamine-induced blockade of carotenogenesis has been proposed to result from the inhibition of dehydrogenases that desaturate the intermediate, phytoene, to form $\beta$-carotene. Inhibition of carotenogenesis by diphenylamine results in an accumulation of phytoene.

White light (3500 lux) from a fluorescent lamp was irradiated during the incubation period of a fermentation of $R$. glutinis. Methylene blue (MB), methylviologen (MV) and AAPH [2,2'-azobis(2amidinopropane) dihydrochloride] were used as generators of singlet oxygen, superoxide anions and peroxyl radicals, respectively. All the generators enhanced the carotenoid biosynthesis, particularly MV which indicated remarkable effectiveness. However, no generator enhanced the production of $\beta$-carotene, whereas each active oxygen species and radical enhanced that of torularhodin and torulene. Production of the latter increased up to about twofold, and a 2.0- to 2.5fold increase was observed for torularhodin production. Torulene and torularhodin were produced at a total quantity of $1.5 \mathrm{mg} / 100 \mathrm{~g} \mathrm{cdw}$ (cell dry weight), which was approximately double that produced in the non-added group (0.75 $\mathrm{mg} / 100 \mathrm{~g} \mathrm{cdw}$ ). The result showed that oxidative loading activated the pathway for torularhodin production.

Torularhodin showed increased production even after MV was added, and torularhodin was presumed to have the inherent capacity to eliminate superoxide anion. These results suggested that superoxide anions generated by the addition of MV were not responsible for torularhodin production by way of direct interaction with yeast cells. It appeared that increased production of torularhodin did not result from the presence of superoxide anions in the medium, but instead, it occurred as a preventive and protective response against subsequent chain reaction of lipoperoxidation. The addition of MB, which generated singlet oxygen, resulted in an increased production of torularhodin, possibly due to removal of singlet oxygen (Sakaki et al. 2002).

\section{Antioxidant and Pro-vitamin A Activity}

Torularhodin has been demonstrated to protect against oxidative stress and is considered to be one of the most important carotenoids for such protection among the carotenoids produced in yeasts. The abilities of $\beta$-carotene and torularhodin to quench singlet oxygen were evaluated by monitoring, in the presence of the two carotenoids, DPBF (2,5-diphenyl-3.4benzofran) decomposition caused by singlet oxygen generated from EPA (3-(1,4-Epidioxyl-4methyl-1.4-dehydro-1-naphtyl)propionic acid) (Table 2). When $\beta$-carotene and torularhodin were added at the same molar concentration, the decomposition of DPBF in the presence of torularhodin was slower than that in the presence of $\beta$-carotene. This indicated that torularhodin more effectively quenched singlet oxygen than $\beta$-carotene (Sakaki et al. 2002).

Table 2 - Comparison of torularhodin and torulene antioxidant and provitamin A activity.

\begin{tabular}{lcc}
\hline & $\begin{array}{c}\text { Decomposition } \\
\text { of DPBF (mM/h) }\end{array}$ & $\begin{array}{c}\text { Relative } \\
\text { vitamin A activity }\end{array}$ \\
\hline Control & $0.023^{1}$ & \\
$\tilde{\beta}$ carotene & $0.013^{1}$ & $100 \%^{2}$ \\
Torularhodin & $0.002^{1}$ & \\
Torulene & n.a. & $75 \%{ }^{2}$ \\
\hline References: 1$)($ Sakaki et al. 2002) 2) (Simpson 1983).
\end{tabular}

It is likely that the more potent quenching ability of torularhodin is due to its longer polyene chain (Sakaki et al. 2001). The antioxidant effect of carotenoids has been determined (a) by varying the peripherals (rings, substituents) keeping the polyene chain constant, or (b) by keeping the peripherals constant varying the chain lengths. However, it is commonly assumed that the longer the polyene chain, the better the antioxidant properties. On the other hand, systematic measurements with different carotenoids have suggested an optimal chain length for diverse functions, e.g., 11 double bonds for singlet oxygen quenching, 7 and 11 or 9 and 11 double bonds for photo bleaching protection, 10 or 9 and 11 double bonds for light harvesting function, and 7 double bonds for photon-to-current conversion (solar cell) (Zaidi et al. 2013).

Some carotenoids are precursors of vitamin A, which is formed by the enzymatic hydrolysis of 
the carotenoid molecule (Maldonade et al. 2008; Irazusta et al. 2013). Torularhodin has the requirement for provitamin $\mathrm{A}$ activity, i.e., a $\beta$-ring without substituents and a lateral polyene chain of 11 carbons (Maldonade et al. 2008), and has an provitamin A activity which is $75 \%$ that of $\beta$-carotene (Simpson 1983).

Besides the antioxidant and vitamin activity of carotenoids, other effects such as antiinflammatory and antimutagenic have been investigated. Rats infected with Helicobacter pylori had been fed with the diets supplemented with carotenoids, and the gastric inflammation decreased significantly, as well as the quantity of the bacteria population (Amaro et al. 2013). In the tests for inhibition of mutagenicity induced by aflatoxin $\mathrm{B}_{1}\left(\mathrm{AFB}_{1}\right)$, benzo[a]pyrene $(\mathrm{BaP})$, 2amino-3-methylimidazo [4,5-f]quinolone (IQ), and cyclophosphamide (CP) in histidine-deficient strains of Salmonella typhimurium, it was found that torularhodin had a weak activity: the maximum inhibition did not exceed $40 \%$ (Rauscher et al. 1998). There are some studies that relate damaging effects of carotenoids in chronic doses, especially in the populations considered at "risk", like smokers (Elliott 2005). Apparently antioxidant molecules reduce the expression of genes involved in the endogenous system of protection against free radicals, suppressing the signalization of tumor cells, allowing them to proliferate (Sayin et al. 2014). In the case of torulene and torularhodin, those studies are still in course (Zoz 2014).

\section{PRODUCTION OF TORULENE AND TORULARHODIN}

Torulene and torularhodin may be produced in suitable liquid cultures. During the cultivation of carotenogenic microrganisms, maximum torulene and torularhodin production seemed to occur after the exponential phase (Buzzini and Martini 1999). On the study of kinetics of Rhodotorula aurantiaca production of pigments was evaluated, it was possible to identify that torulene and torularhodin were produced significant amounts: torulene $(73 \mu \mathrm{g} / \mathrm{g})$ at the logarithmic phase and torularhodin $(130 \mu \mathrm{g} / \mathrm{g})$ at stationary phase (Bonaly and Malenge 1968).

Torulene and torularhodin are intracellular pigments in all the producer microorganisms, and being fat-soluble compounds they are found in the lipid-rich regions of the cell (Rumi Jr. et al. 2001).
The amount produced depends highly on the microorganism and on the medium chosen, as shown in Table 3. The carotenoid pigments produced by $R$. graminis DB- VPG 7021 were identified as $\beta$-carotene $(50.3 \%$ of total carotenoids), $\quad \gamma$-carotene $(15.4 \%), \quad$ torulene (22.7\%) and torularhodin (11.6\%) by comparison of their chromatographic and UV-VIS spectroscopic properties (Buzzini et al. 2005). These pigments are often produced in batch fermentations. The process takes 5-7 days at $27^{\circ}$ to $30^{\circ} \mathrm{C}$ (Buzzini and Martini 1999).

Light and darkness are very important factors that affect the carotenogenesis. In a 1968 study with Epicoccum nigrum, it was observed that the total amount of carotenoids produced in darkness were $5 \%$ higher per gram of dry weight, compared to normal growth conditions at 110 lux. The carotenoid content was about $7 \%$ higher at 2000 lux and about 25\% higher at 2500 lux, with a tendency towards the more highly oxygenated carotenoids. In E. nigrum, light act as an inhibitor of carotenogenesis, or as a destroyer of synthesized pigments (Gribanovski-Sassu and Foppen 1968). Weak white light also affected the growth and stimulated carotenogenesis in $R$. glutinis (Sakaki et al. 2001).

After $72 \mathrm{~h}$ normal cultures contained $\beta$-carotene, $\gamma$-carotene, rhodoxanthin and torularhodin, whereas the addition of diphenylamine for only $5 \mathrm{~h}$ resulted an extremely rapid production of phytoene, and to some extent, of lycopene, and a complete loss of rhodoxanthin and torularhodin (Foppen and Gribanovski-Sassu 1969). A similarly study reported both $\beta$-carotene and torularhodin present in the diphenylamine plus $\beta$-carotenesupplemented cells, although the amount of torularhodin was approximately $20 \%$ of that of $\beta$-carotene (Moore et al. 1989).

Lower temperatures seemed to favor the synthesis of $\beta$-carotene and torulene whereas higher temperatures positively influenced torularhodin synthesis. Particularly, significant differences $(\mathrm{P}<0.01)$ were found between $25^{\circ} \mathrm{C}$ and $30^{\circ} \mathrm{C}$ (Buzzini and Martini 1999). The increase 25 to $30^{\circ} \mathrm{C}$ resulted reduction in $\beta$-carotene from 16 to $9.3 \%$ and torulene from 18 to $9.4 \%$ of the total carotenoids, while torularhodin increased from 60.1 to $78.7 \%$. Ultraviolet light irradiation causes effects on carotenogenesis too. In a study cell damage of Rhodotorula glutinis was evaluated based on leakage of lactate dehydrogenase (LDH) 
into the cultivation medium. The cells were incubated for 3 to 5 days at $30^{\circ} \mathrm{C}$ with reciprocal shaking at $120 \mathrm{rpm}$ with a $5 \mathrm{~cm}$ span, with illumination from a fluorescent lamp, with the wavelength controlled using color filters. In the examination of tolerance to active oxygen species, MB (methylene blue) was added to the medium as a generator of singlet oxygen. LDH activity in the cultivation medium was determined before and after the addition of MB. After irradiation with ultraviolet light, a reddish colony, which exhibited a color tone markedly deeper than that of the parent strain, was obtained. Torularhodin production was about four times that of the parent strain. It was suggested that torularhodin producing mutants exhibited resistance to oxidative stress due to the addition of MB (Sakaki et al. 2000). Another similar study was done with Sporobolomyces ruberrimus and Cystofilobasidium capitatum, where pigmented strains of these yeasts had a higher survival when compared with albino strains of the same species, after UV irradiation, also with an increase on the production of torularhodin (Moliné et al. 2009). The parent yeast, $R$. glutinis no. 21, was proven capable of increasing the production of torularhodin when incubated under an oxidative stress by aeration. These findings reflect a priority for torularhodin synthesis under an oxidative load in a test strain biosynthesizing $\beta$-carotene and torularhodin (Sakaki et al. 2000).

Table 3- Production of Torulene and Torularhodin depending on the medium and microorganism chosen.

\begin{tabular}{|c|c|c|c|c|}
\hline Microorganism & Substrate/Conditions & Torulene & Torularhodin & Reference \\
\hline \multirow{9}{*}{ Rhodotorula glutinis } & Grape Must Concentrate & $85.13 \mu \mathrm{g} / \mathrm{g}$ dry cells & $721.33 \mu \mathrm{g} / \mathrm{g}$ dry cells & \multirow{6}{*}{$\begin{array}{l}\text { Buzzini and } \\
\text { Martini } 1999\end{array}$} \\
\hline & Grape Must & $35.98 \mu \mathrm{g} / \mathrm{g}$ dry cells & $297.38 \mu \mathrm{g} / \mathrm{g}$ dry cells & \\
\hline & Glucose Syrup & $25.92 \mu \mathrm{g} / \mathrm{g}$ dry cells & $204 \mu \mathrm{g} / \mathrm{g}$ dry cells & \\
\hline & Beet Molasses & $31.95 \mu \mathrm{g} / \mathrm{g}$ dry cells & $268.57 \mu \mathrm{g} / \mathrm{g}$ dry cells & \\
\hline & Soybean Flour Extract & $96.28 \mu \mathrm{g} / \mathrm{g}$ dry cells & $708.41 \mu \mathrm{g} / \mathrm{g}$ dry cells & \\
\hline & Maize Flour Extract & $57.11 \mu \mathrm{g} / \mathrm{g}$ dry cells & $285.57 \mu \mathrm{g} / \mathrm{g}$ dry cells & \\
\hline & Seawater Medium & $\begin{array}{l}30 \mathrm{mg} / \mathrm{L} * \text { decrease in } \\
\text { comparison with b- } \\
\text { carotene }(60 \mathrm{mg} / \mathrm{L})\end{array}$ & - & $\begin{array}{l}\text { Bhosale and } \\
\text { Gadre } 2001\end{array}$ \\
\hline & Dark & $29.2 \mathrm{mg}$ & $7.9 \mathrm{mg}$ & Sakaki et al. \\
\hline & White Light & $32.2 \mathrm{mg}$ & $14.2 \mathrm{mg}$ & 2001 \\
\hline R. rubra & Aerobic process & - & $\begin{array}{l}81 \mu \mathrm{g} / \mathrm{g}-87 \% \text { of the } \\
\text { total carotenoids }\end{array}$ & $\begin{array}{l}\text { Ungureanu et } \\
\text { al. } 2012\end{array}$ \\
\hline \multirow{5}{*}{$\begin{array}{l}\text { Rhodotorula } \\
\text { aurantiaca }\end{array}$} & $\begin{array}{l}\text { Synthetic medium Solid } \\
\text { - RPM }\end{array}$ & $9.6 \mu \mathrm{g} / \mathrm{g}$ & $120 \mu \mathrm{g} / \mathrm{g}$ & \multirow{5}{*}{$\begin{array}{l}\text { Bonaly and } \\
\text { Malenge } 1968\end{array}$} \\
\hline & Synthetic medium & $7 \mu \mathrm{g} / \mathrm{g}$ & $48 \mu \mathrm{g} / \mathrm{g}$ & \\
\hline & Liquid - RPM & & & \\
\hline & $\begin{array}{l}\text { Synthetic Medium Solid } \\
\text { - CBS } 2200\end{array}$ & $20.5 \mu \mathrm{g} / \mathrm{g}$ & $101 \mu \mathrm{g} / \mathrm{g}$ & \\
\hline & $\begin{array}{l}\text { Synthetic Medium } \\
\text { Liquid - CBS } 2200\end{array}$ & $11.5 \mu \mathrm{g} / \mathrm{g}$ & $21 \mu \mathrm{g} / \mathrm{g}$ & \\
\hline \multirow{8}{*}{$\begin{array}{l}\text { Rhodotorula } \\
\text { mucilaginosa-135 } \\
\text { Rhodotorula } \\
\text { mucilaginosa-137 } \\
\text { Rhodotorula } \\
\text { graminis-125 } \\
\text { Rhodotorula } \\
\text { mucilaginosa-108 } \\
\text { Rhodotorula } \\
\text { mucilaginosa-12 } \\
\text { Rhodotorula glutinis } \\
\text { Rhodotorula minuta } \\
\text { Sporobolomyces }\end{array}$} & YM broth & $365 \mu \mathrm{g} / \mathrm{L}$ & $47 \mu \mathrm{g} / \mathrm{L}$ & \multirow{8}{*}{$\begin{array}{l}\text { Maldonade } \\
\text { et al. } 2008\end{array}$} \\
\hline & YM broth & $352 \mu \mathrm{g} / \mathrm{L}$ & $24 \mu \mathrm{g} / \mathrm{L}$ & \\
\hline & YM broth & $186 \mu \mathrm{g} / \mathrm{L}$ & Traces & \\
\hline & YM broth & $307 \mu \mathrm{g} / \mathrm{L}$ & $65 \mu \mathrm{g} / \mathrm{L}$ & \\
\hline & YM broth & $372 \mu \mathrm{g} / \mathrm{L}$ & $10 \mu \mathrm{g} / \mathrm{L}$ & \\
\hline & YM broth & $261 \mu \mathrm{g} / \mathrm{L}$ & $20 \mu \mathrm{g} / \mathrm{L}$ & \\
\hline & YM broth & Traces & Traces & \\
\hline & YM broth & $71 \mu \mathrm{g} / \mathrm{L}$ & $10 \mu \mathrm{g} / \mathrm{L}$ & \\
\hline \multirow{6}{*}{$\begin{array}{l}\text { Sporobolomyces } \\
\text { ruberrimus }\end{array}$} & Glycerol & - & $\begin{array}{l}285.71 \mu \mathrm{g} / \mathrm{g} \\
0.81 \mathrm{mg} / \mathrm{g}\end{array}$ & Cardoso 2008 \\
\hline & \multirow{2}{*}{ Technical glycerol } & - & $276.44 \mu \mathrm{g} / \mathrm{g}$ & \multirow{5}{*}{$\begin{array}{l}\text { Cardoso } 2008 \\
\text { Razavi } 2006 \\
\text { Gonçalves } 2012 \\
\text { Zoz } 2014 \\
\text { Gonçalves } 2012 \\
\end{array}$} \\
\hline & & - & $3.55 \mathrm{mg} / \mathrm{g}$ & \\
\hline & \multirow{3}{*}{$\begin{array}{l}\text { YM broth } \\
\text { Sugar cane molasses }\end{array}$} & - & $3840 \mu \mathrm{g} / \mathrm{g}$ & \\
\hline & & 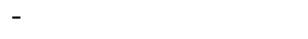 & $20.83 \mu \mathrm{g} / \mathrm{g}$ & \\
\hline & & - & $2624 \mu \mathrm{g} / \mathrm{g}$ & \\
\hline
\end{tabular}


The increase in torularhodin depends not only on the number of yeast cells exposed to light irradiation but may also be affected by their physiological conditions (Sakaki et al. 2001). The supplementation of culture media with $\mathrm{Cu}$ (II) as $\mathrm{CuSO}_{4}$ produced a remarkable change in pigmentation intensity of $R$. mucilaginosa RCL11. The addition of $0.5 \mathrm{mM} \mathrm{CuSO}_{4}$ to the culture medium produced a two-fold increase in carotenoid synthesis, from $1.7 \mathrm{mg} . \mathrm{l}^{-1}$ in the control culture to $3.3 \mathrm{mg}^{-1}$ with the copper supplementation.

Carotenoid production of $R$. mucilaginosa RCL-11 is related to specific responses to different stress conditions. Heavy metal addition not only changed the concentration but also the relative profile of the carotenoids synthesized by $R$. mucilaginosa RCL-11. However, the modification of the culture conditions, i.e., the addition of heavy metals such as copper, could be a promising way to increase the yield of these compounds by the microorganisms for which molecular techniques have not been developed. The connection between the carotenoid biosynthesis and the oxidative stress response of $R$. mucilaginosa RCL-11 triggered by the heavy metal exposure is highlighted by the modification of the carotenoid profile when the yeast cells are cultured with copper and hydrogen peroxide. The examination of the relative pigment proportions shows that under $\mathrm{Cu}(\mathrm{II})$ exposure, the relative percentage of torulene and the appearance of $\gamma$-carotene are favored in detriment of $\beta$-carotene. When yeast cultures were supplemented with $\mathrm{H}_{2} \mathrm{O}_{2}$ alone, the main changes observed were related to the total carotenoid amount, the detection of the precursor $\gamma$-carotene, and inverted percentages between torularhodin and torulene. It is, therefore, possible that this stressor not only induces the changes in the amounts of the carotenoids, but also in a specific carotenoid response (Irazusta et al. 2013).

A problem for the maximization of biosynthesis of a specific ketocarotenoid is the formation of byproducts. The more functional groups are introduced into $\gamma$-carotene and torulene, the more intermediates and other end products can be expected (Sandmann et al. 2006). In order to produce TR and TRA more economically, it is necessary to increase the intracellular carotenoid concentration, use low-cost culture media (i.e. utilizing industrials wastes), increase the efficiency of extraction and direct the biosynthetic pathway towards torulene (Maldonade et al. 2008).

\section{Extraction of torulene and torularhodin}

The carotenoid pigments of yeasts accumulate in lipid droplets and can thus be extracted with a variety of organic solvents. The efficient extraction of the intracellularly produced carotenoids of $R$. glutinis may require efficient disruption of the rigid cell wall of the yeast. Acid treatment may be used to disrupt the cellular membranes of yeast cells. However, acid treatment may result in considerable carotenoid damage. Other carotenoid extraction methods based on enzymatic cell wall disruption and supercritical carbon dioxide extraction have also been reported (Park et al. 2007). The differences in the extraction results may be attributed to differences in (i) the ability of a given solvent to permeabilize the yeast cell wall and/or (ii) the solubility of carotenoids in a given solvent (Park et al. 2007). When multiple solvents were used together to disrupt the cell wall of $R$. glutinis and thus release the cellular carotenoid pigments, they demonstrated a synergistic effect on the extent of carotenoid recovery. The three solvents tested, namely, dimethyl sulfoxide, petroleum ether, and acetone, were adequate for the extraction of carotenoids (Park et al. 2007). The same conclusion was obtained by Kaiser et al. (2007) using the same microorganism, $R$. glutinis, that for a better disruption of yeasts cells and pigments recovery, a mixture of various solvents is the better choice. The optimum combination of the three solvents improved the extent of carotenoid recovery compared with individual solvents (Park et al. 2007).

Other mechanism for the extraction of these pigments is a combination of a solvent (DMSO) with a mechanic method of cell disruption, like agitation of the material with treated sand (Squina and Mercadante 2003). Carotenoids from $R$. glutinis produced in seawater medium are reportedly of easy extraction, without mechanical disintegration of the cell mass, due to the $\mathrm{pH}$ of the medium (Bhosale and Gadre 2001). Early experiments were made upon yeast pigment recovery by centrifugal partition extraction. A $91 \%$ recovery of torularhodin of $R$. rubra was obtained in few minutes. The technique did not require a preliminary drying, as often described for hydrophobic compounds extraction. As apparatuses volumes go from $50 \mathrm{~mL}$ to several liters, the technique is adequate for sample preparation (metabolites analysis from crude bio products) up to larger scale downstream processes 
for the direct extraction of fractions at the bioreactor outlet. The biphasic system used for the extraction is hexane/water with acetone as the 'bridge solvent'. The Hex/ACO/W (v/v/v) composition of the stationary phase and the mobile phase were 29/71/0 and 2/62/36, respectively. The wet biomass ( $40 \mathrm{~g})$ ( $7.16 \mathrm{~g}$ dry weight) obtained by the biosynthesis was mixed with $73 \mathrm{~mL}$ water, $126 \mathrm{~mL}$ acetone and $4 \mathrm{~mL}$ hexane, and the solvent stationary phase was $89 \mathrm{~mL}$ acetone and $216 \mathrm{~mL}$ hexane. The extraction was performed in the descending mode (Ungureanu et al. 2012).

\section{Purification of torulene and torularhodin}

For purification of these sensible molecules, chromatography is the method most utilized. There are many variations of the mobile phases: $10 \%$ acetone to elute torulene and $20 \%$ do total to elute torularhodin, for example (Valadon and Cooke 1962).

Torularhodin of E. nigrum could be identified by its very strong absorbance on Florisil and alumina columns as an acidic carotenoid. The solvents used were Hexane: Acetone 90:10 (Gribanovski-Sassu and Foppen 1966). It is believed that a simple HPLC-chromatographic method is sufficient because most yeast tend to produce only a limited number of carotenoids. Separation of the carotenoids of different polarity has been achieved using a common $\mathrm{C}_{18}$ stationary phase and a plain water/acetone gradient as the mobile phase (Weber et al. 2007). Large-scale processes for the production of these pigments are not yet described in the literature.

\section{USES OFTORULENEANDTORULARHODIN}

Probably because torulene and torularhodin have not been detected in foods, their possible effects on human health have not been studied yet (Maldonade et al. 2008).

However, if the structural characteristics of the molecules of these pigments are characterized, and considering its proven activity as pro-vitamin A and antioxidants, and its possible activities as antitumoral or immunoenhancer, it is clear that these substances may be used as food, feed and cosmetic additives.

In fact, there are species of yeasts that contain these pigments, like Rhodotorula, that are used for animal feeding (e.g. chicken feed, where the yeast aids in increasing body fat, gives better appearance and increases the nutritional properties of the meat) (Castelo Branco 2010).

As a pigment, torulene might be used in the same way as other hydrocarbon carotenoids such as beta carotene or lycopene, thus being a novel red hue to be used as an additive. Torularhodin, at the other side, is an acidic carotenoid and might be used in the same way as bixin and norbixin, the major carotenoids of annatto extract; an obvious use would as a substitution of these in meat products. As an antioxidant, torulene and torularhodin could be used in the same way as potent carotenoid antioxidants such as astaxanthin and lycopene, and again torularhodin could be of advantage in specific formulations because of its carboxyl group, which may enhance its solubility in aqueous formulations.In any of these cases, the technology for formulation of the carotenoids would be the same that already existed for other carotenoids: solutions of the extract in edible oils, oil-in-water emulsions of the pigments, dispersible powders (De Carvalho et al. 2014).

\section{CONCLUSION}

Torulene and torularhodin may have important future uses, but much research is still needed for these and other carotenoids. Their metabolic roles in the microorganisms have not yet been fully clarified, nor has their nutraceutical effect in humans. Recently, a novel function of carotenoids in humans, the inhibition of melanin synthesis, has been reported. Studies on the applications torularhodin are expected to be carried out in the future (Sakaki et al. 2001). Several other carotenoids are important molecules for the pharmaceutical, chemical and food industries, and the specific characteristics torulene and especially torularhodin - and acidic carotenoid - are traits that may ensure its place as industrial additives. For that to happen, the production should be enhanced - and the mutagenesis of the pigmented yeast has been proposed to obtain over-producing strains (Irazusta et al. 2013). At the same time, the evaluation of the physiological effects of these carotenoids will show whether they are safe or not as food and cosmetic additives.

\section{REFERENCES}

Aksu Z, Eren AT. Carotenoids production by the yeast Rhodotorula mucilaginosa: Use of agricultural wastes as a carbon source. Process Biochem. 2005; 40: 29852991. 
Amaro HM, Barros R, Guedes AC, Sousa-Pinto I, Malcata FX. Microalgal compounds modulate carcinogenesis in the gastrointestinal tract. Trends Biotechnol. 2013; 31: 92-98.

An GH, Cho MH, Johnson EA. Monocyclic carotenoid biosynthetic pathway in the yeast Phaffia rhodozyma (Xanthophyllomyces dendrorhous). J Bios Bioeeng. 1999; 88: 189-193.

Avalos J, Mackenzie A, Nelki DS, Bramley PM. Terpenoid biosynthesis in cell extracts of wild-type and mutant strains of Gibberella fujikuroi. Biochim Biophys Acta. 1988; 966: 257-265.

Balashov SP, Imasheva ES, Boichenko VA, Antón J, Wang JM, Lanyi JK. Xanthorhodopsin: a proton pump with a light-harvesting carotenoid antenna. Science. 2005; 76: 53-55.

Bhosale P, Gadre RV. Production of $\beta$-carotene by a Rhodotorula glutinis mutant in sea water medium. Bioresource Technol. 2001; 76:53-55.

Bjerkeng B, Peisker M, Schwartzenberg K, Ytrestoyl T, Asgard T. Digestibility and muscle retention of astaxanthin in Atlantic Salmon, Salmon salar, fed diets with the red yeast Phaffia rhodozyma in comparison with synthetic formulates astaxanthin. Aquacult. 2007; 269:476-489.

Bonaly R, Malenge JP. Biosynthese des carotenoides cycliques chez Rhodotorula mucilaginosa et Rhodotorula aurantiaca. Biochim Biops Acta. 1968; 164:306-316.

Breierová E, Gregorb T, Marova I, Certikd MC, Kogana G. Enhanced antioxidant formula based on a selenium-supplemented carotenoid-producing yeast biomass. Chem Biodiv. 2008; 5: 440-446.

Buzzini P, Martini A, Gaetani M, Turchetti B, Pagnoni UM, Davoli P. Optimization of carotenoid production by Rhodotorula graminis DBVPG 7021 as a function of a trace element concentration by means of response surface analysis. Enz Microbiol Technol. 2005; 36: 687-692.

Buzzini P, Martini A. Production of carotenoids by strains of Rhodotorula glutinis cultured in raw materials of agro-industrial origin. Bioresource Technol. 1999; 71: 41-44.

Cardoso, LAC. Identification de facteurs opératoires influents en vue d'une production microbienne optimale de torularhodine et de sa fonctionnalisation enzymatique, à partir d'études cinétiques [Thèse Docteur] Nancy, França: Institut national polytechnique de Lorraine; 2008.

Castelo Branco LS. Estudo da ampliação de escala na produção de biomassa de Rhodotorula sp. CNPAT02 em processo batelada para obtenção de carotenoides [Dissertação Mestrado]. Fortaleza, Brasil: Centro de Tecnologia Universidade Federal do Ceará, 2010.

Czeczuga B. The presence of carotenoids in various species of Lepidoptera. Biochem System. 1986; 14: 345-51.
De Carvalho JC, Cardoso LC, Ghiggi V, Woiciechowski AL, Vandenberghe LPS, Soccol CR. Microbial Pigments. Biotransformation of Waste Biomass into High Value Biochemicals, Springer: 2014:73-97.

Elliot R. Mechanisms of genomic and non-genomic actions of carotenoids. Biochim Biophys Acta. 2005; 1740: 147-154.

Estrada AF, Maier D, Scherzinger D, Avalos J, AlBabili S. Novel apocarotenoid intermediates in Neurospora crassa mutants imply a new biosynthetic reaction sequence leading to neurosporaxanthin formation. Fung Gen Biol. 2008; 45: 1497-1505.

Foppen FH, Gribanovski-Sassu O. Carotenogenesis in diphenylamine-treated Epicoccum nigrum link. Biochim Biophys Acta.1969; 176:357-366.

Gonçalves VN. Produção e extração de carotenoides produzidos por Sporobolomyces ruberrimus utilizando subprodutos industriais [Dissertação Mestrado]. Curitiba, Brasil: Universidade Positivo; 2012.

Gorbushina AA, Kotlova ER, Sherstneva OA. Cellular responses of microcolonial rock fungi to long-term desiccation and subsequent rehydration. Stud Mycol. 2008; 61: 91-97.

Gribanovski-Sassu O, Foppen FH. Light and temperature effect on Epicoccum nigrum. Phytochem. 1968; 7: 1605-1612.

Gribanovski-Sassu O, Foppen FH. The Carotenoids of the fungus Epicoccum nigrum link. Phytochem. 1966; 6: 907-909.

Hausmann A, Sandmann G. A single five-step desaturase is involved in the carotenoid biosynthesis pathway to $\beta$-carotene and torulene in Neurospora crassa. Fung Gen Biol. 2000; 30: 147-153.

Herz S, Weber RS, Anke H, Mucci A, Davoli P. Intermediates in the oxidative pathway from torulene to torularhodin in the read yeasts Cystofilobasidium infirmominiatum and $C$. capitatum (Heterobasidiomycetes, Fungi). Phytoc. 2007; 68:2503-2511.

Irazusta V, Nieto-Peñalver CG, Cabral ME, Amoroso MJ, Figueroa LC. Relationship among carotenoid production, copper bioremediation and oxidative stress in Rhodotorula mucilaginosa RCL-11. Proc Biochem. 2013; 48: 803-809.

Kaiser P, Surmann P, Vallentin G, Fuhrmann, H. A small-scale method for quantitation of carotenoids in bacteria and yeasts. J Microb Met. 2007; 70: 142-149.

Madhour A, Anke H, Mucci A, Davoli P, Weber RS. Biosynthesis of the xanthophyll plectaniaxanthin as a stress response in the red yeast Dioszegia (Tremellales, Heterobasidiomycetes, Fungi). Phytoch. 2005; 66:2617-2626.

Maldonade IR, Rodriguez-Amaya DB, Scamparini AR. Carotenoids of yeasts isolated from the Brazilian ecosystem. Food Chem. 2008; 107:145-150. 
Maoka T. Sterically hindered carotenoids with 3Z, 5Z configuration from the seeds of oriental bitter sweet, Celastrus orbiculatus. Phytochem. 2009; 70:920-923.

Méndez-Álvarez S, Rüfenacht K, Eggen RL. The Oxidative Stress-Sensitive yapl null strain of Saccharomyces cerevisiae becomes resistant due to increased carotenoid levels upon the introduction of the Chlamydomonas reinhardtii cDNA, coding for the 60S ribosomal protein L10a. Bioc Biop R Comm. 2000; 267: 953-959.

Moliné M, Flores MR, Libkind D, Diéguez MC, Farías ME, Broock M. Photoprotection by carotenoid pigments in the yeast Rhodotorula mucilaginosa: the role of torularhodin. Photochem Photobiol Scien. 2010; 9: 1145-1151.

Moore MM, Breedveld MW, Autor AP. The role of carotenoids in preventing oxidative damage in the pigmented yeast, Rhodotorula mucilaginosa. Arch of Biochem Biophys. 1989; 270: 419-431.

Moriel DG, Chociai MB, Machado IMP, Fontana JD, Bonfim TMB. Effect of feeding methods on the astaxanthin production by Phaffia rhodozyma in fedbatch process. Braz Arch Biol Techn. 2005; 48(3): 397-401.

Ni H, He GQ, Ruan H, Chen QH, Chen F. Application of derivative ratio spectrophotometry for determination of $\beta$-carotene and astaxanthin from Phaffia rhodozyma extract. J Zhej Univ Scien. 2005; 6: 514-522.

Park PK, Kim EY, Chu KH. Chemical disruption of yeast cells for the isolation of carotenoid pigments. Sep Pur Technol. 2007; 53: 148-152.

Rauscher R, Edenharder R, Platt KL. In vitro antimutagenic and in vivo anticlastogenic effects of carotenoids and solvent extracts from fruits and vegetables rich in carotenoids. Mut Res. 1998; 413: 129-142.

Razavi SH, Marc I. Effect of temperature and $\mathrm{pH}$ on the growth kinetics and carotenoid production by Sporobolomyces ruberrimus $\mathrm{H} 110$ using technical glycerol as carbon source. Iran J Chem Eng. 2006; 25: 59-64.

Rumi Jr G, Matus Z, Toth G, Par A, Nagy Z, Vincze A. Changes of serum carotenoids in patients with esophageal, gastric, hepatocellular, pancreatic and colorectal cancer. J Phys - Paris. 2001, 95: 239-242.

Sakaki H, Nakanishi T, Satonaka KY, Miki W, Fujita T, Komemushi S. Properties of a high-torularhodinproducing mutant of Rhodotorula glutinis cultivated under oxidative stress. J Biosci Bioeng. 2000; 89: 203-205.

Sakaki H, Nakanishi T, Tada A, Miki W, Komemushi S. Activation of torularhodin production by Rhodotorula glutinis using weak light irradiation. $J$ Biosci Bioeng. 2001; 92: 294-297.
Sakaki H, Nochide H, Komemushi S, Miki W. Effect of active oxygen species on the productivity of torularhodin by Rhodotorula glutinis No. 21. J Biocis Bioeng. 2002; 3: 338-340.

Sandmann G, Zhu C, Krubasik P, Fraser PD. The biotechnological potential of the al-2 gene from Neurospora crassa for the production of monocyclic keto hydroxy carotenoids. Bioc Biop Acta. 2006; 1761: 1085-1092.

Sayin VI, Ibrahim XM, Larsson E, Nilsson JA, Lindahl $\mathrm{P}$, Bergol MO. Antioxidants accelerate lung cancer progression in mice. Scien Transl Med. 2014; 6: 1-8.

Schrantz JP, Lemoine Y. Carotenoid composition of mycelium and apothecia in the discomycete Scutellinia umbrarum. Phytochem. 1995; 40: 33-35.

Simpson KL. Relative value of carotenoids as precursors of vitamin A. Proc Nutr Soc. 1983; 42(01): 7-17.

Squina FM, Mercadante AZ. Análise, por CLAE, de carotenoids de cinco linhagens de Rhodotorula. Braz J Pharm Scien. 2003; 39: 309-318.

Stoytcheva M, Montero G. Biodiesel - feedstocks and processing technologies. InTech. 2011: 2458.

Tinoi J, Rakariyatham N, Deming RL. Simplex optimization of carotenoid production by Rhodotorula glutinis using hydrolyzed mung bean waste flour as substrate. Proc Biochem. 2005; 40: 2551-2557.

Ungureanu C, Marchal L, Chirvase AA, Foucault A. Centrifugal partition extraction, a new method for direct metabolites recovery from culture broth: Case study of torularhodin recovery from Rhodotorula rubra. Bioresource Technol. 2012; 1-4.

Valadon LRG, Cooke RC. Carotenoid pigments of the nematode-trapping hyphomycete Arthrobotrys oligospora (Fres.) Phytochemistry. 1962;2:103-105.

Villoutreix J. Les caroténoïdes de Rhodotorula mucilaginosa étude de leur biosynthèse a l'aide de l'analyse de mutants et de l'emploi d'un inhibiteur de la caroténogénèse. Biochim Biophys Acta 1960;40: 442-457.

Weber RS, Anke H, Davoli P. Simple method for the extraction and reversed-phase high-performance liquid chromatographic analysis of carotenoid pigments from red yeasts (Basidiomycota, Fungi). $J$ Chrom. 2007; 1145:118-122.

Zaidi A, Li H, Sliwka HR, Partali V, Ernst H, Melo TB. Energy and electron transfer reactions of polyenic acids with variable chain lengths. Tetrah. 2013; 69: 219-227.

Zoz, LIC. Avaliação dos efeitos do extrato bruto de levedura Sporobolomyces ruberrimus em ratos [Dissertação Mestrado]. Curitiba, Brasil: Universidade Positivo; 2014. 